\title{
Diretrizes para o planejamento de uma demolição seletiva em edifícios
}

\author{
Guidelines for planning a selective demolition on buildings
}

\section{Lignes directrices pour la planification d'une démolition sélective dans les bâtiments}

\section{Directrices para la planificación de una demolición selectiva en edificios}

\author{
Andreia Sofia Moreira Martins ${ }^{1}$ \\ Daniel Costa Reis ${ }^{2}$ \\ Márcio Minto Fabricio²
}

Recebido em 10/10/2017; revisado e aprovado em 15/02/2018; aceito em 13/02/2018

DOI: http://dx.doi.org/10.20435/inter.v0i0.1732

\begin{abstract}
Resumo: O objetivo do presente artigo é desenvolver um conjunto de diretrizes que permitam aprimorar o planejamento das atividades de demolição e promover práticas mais sustentáveis no canteiro de obras de demolição. A pesquisa empírica foi realizada através de três estudos de caso, desenvolvendo um diagnóstico do funcionamento das atividades das empresas que praticam a demolição seletiva de pequenas edificações, através de entrevistas, acompanhamento das demolições e da revenda dos materiais. Assim sendo, foi possível verificar a existência de mercados para os materiais e componentes reaproveitados que promovem o desenvolvimento local.
\end{abstract}

Palavra-chave: demolição tradicional; demolição seletiva; desconstrução; gestão de resíduos de demolição; reutilização.

\begin{abstract}
The objective of this article is to develop a set of guidelines that allow to improve the planning of the demolition activities and to promote more sustainable practices in the construction site. The empirical research was carried out by the application of three case studies, developing a diagnosis of the operation of the activities of the companies practicing the selective demolition in small buildings, through interviews, monitoring the demolitions and the resale of the materials. Thus, it was possible to verify the existence of markets for recycled materials and components that promote local development.
\end{abstract}

Keywords: conventional demolition; selective demolition; deconstruction; demolition waste management; reuse.

Résumé: L'objectif de cet article est de développer un ensemble de lignes directrices qui permettent d'améliorer la planification des activités de démolition et de promouvoir des pratiques plus durables sur le chantier de construction. La recherche empirique a été réalisée par l'application de trois études de cas, en développant un diagnostic du fonctionnement des activités des entreprises qui pratiquaient la démolition sélective dans de petits bâtiments, par des entretiens, le suivi des démolitions et la revente des matériaux. Ainsi, il a été possible de vérifier l'existence de marchés pour les matériaux recyclés et les composants qui favorisent le développement local.

Mots-clés: demolition traditionnelle; demolition selective; deconstruction; demolition gestion des dechets; reutilisation.

Resumen: El objetivo del presente artículo es desarrollar un conjunto de directrices que permiten mejorar la planificación de las actividades de demolición y promover prácticas más sostenibles en el sitio de obras. La investigación empírica fue realizada por la aplicación de tres estudios de caso, desarrollando un diagnóstico del funcionamiento de las actividades de las empresas que practican la demolición selectiva en pequeñas edificaciones, a través de entrevistas, seguimiento de las demoliciones y de la reventa de los materiales. Por lo tanto, fue posible verificar la existencia de mercados para los materiales y componentes reaprovechados que promueven el desarrollo local.

Palabras clave: demolición tradicional; demolición selectiva; desconstrucción; gestión de residuos de demolición; reutilización.

\footnotetext{
${ }^{1}$ Universidade Federal de São Carlos (UFSCar), São Carlos, São Paulo, Brasil.

${ }^{2}$ Universidade São Paulo (USP), São Paulo, São Paulo, Brasil.
} 


\section{INTRODUÇÃO}

A construção de edifícios é uma das principais responsáveis pelo consumo de recursos não renováveis, desperdício de materiais e acumulação de resíduos produzidos ao longo da cadeia de produção. O modelo tradicional de construção é responsável pela produção de grandes quantidades de dióxido de carbono $\left(\mathrm{CO}^{2}\right)$ e de outras emissões nocivas aos diferentes ecossistemas, provocando impactos ambientais como inversões térmicas, efeito estufa etc., levando a alterações significativas nos habitats de vários seres vivos (PAIVA; RIBEIRO, 2005). Nesse sentido, é importante incentivar a existência de programas de orientação estratégica que incrementam boas práticas construtivas, isto é, práticas mais sustentáveis, através de mecanismos financeiros (taxas, créditos, penalizações ecológicas, entre outros) (CASTRO; MATEUS; BRAGANÇA, 2012). Para tal, é necessário iniciar nas etapas de projeto e planejamento, a consideração de estratégias que visam à promoção da recuperação de materiais e componentes da construção após a vida útil do edifício (ROCHA, 2007). Face às preocupações ambientais e à oposição pública, estão sendo criados regulamentos para definir planos, com o intuito de reduzir o descarte de resíduos sólidos em aterros sanitários (DANTATA; TOURAN; WANG, 2005). Uma legislação eficaz deve providenciar uma adequada prevenção para minimizar o potencial de poluição ambiental (BANIAS et al., 2010).

De acordo com um estudo realizado por Assefa e Ambler (2017), os materiais de construção de edifícios institucionais no Canadá podem ser reabilitados para uma segunda vida e, em média, prevenir um potencial aquecimento global em torno de 3300 toneladas por edifício reutilizado, o que implicaria a redução da emissão equivalente a 165 megatoneladas de $\mathrm{CO}^{2}$ para a atmosfera. É importante procurar soluções para a fase final das edificações, incentivando a prática de demolições mais sustentáveis ou até manutenções e adaptações contínuas ao edifício. Começando pela escolha dos materiais e componentes que agregam mais valor para as empresas demolidoras locais envolvidas e soluções de projeto que simplifiquem a desmontagem e reutilização de todos os elementos de um edifício.

Este artigo, que é produto de uma pesquisa de mestrado, possui como objetivos: desenvolver diretrizes que permitam aprimorar o planejamento das atividades de demolição de edifícios; identificar as boas práticas na execução dos trabalhos de demolição e na gestão de Resíduos da Construção Civil (RCC), por meio de revisão bibliográfica e da análise de três estudos de caso.

\section{REVISÃO DA LITERATURA}

A partir da década de 90, os resíduos da construção civil tornaram-se objeto de várias pesquisas e publicações científicas, e foi editada, em 2002, a Resolução do Conama n. 307, passando a exigir que os municípios brasileiros implementem um Plano Municipal de Gerenciamento dos Resíduos de Construção Civil (TESSARO; SÁ; SCREMIN, 2012).

De acordo com Vefago e Avellaneda (2013), os resíduos gerados pela construção civil na União Europeia são estimados em aproximadamente 180 milhões de toneladas por ano, o que representa mais de $480 \mathrm{~kg}$ por pessoa por ano, e aproximadamente $75 \%$ dos RCC vão para aterros sanitários. Muitas vezes, são constituídos por elementos perigosos como metais pesados e Compostos Orgânicos Voláteis (COV). Ainda mais graves são os impactos causados pela grande quantidade de RCC no Brasil, onde são depositados clandestinamente em terrenos baldios, córregos e áreas de preservação permanente (MARINHO; SILVA, 2012). 
Conforme Banias et al. (2010), os RCC são provenientes da construção, renovação, reparação e demolição de estruturas, tais como edifícios residenciais e comerciais, estradas, pontes etc. A sua composição varia para essas diferentes atividades e estruturas, contendo volumosos e pesados materiais, incluindo concreto, madeira, asfalto (de estradas), telhas, gesso (do drywall), metais, tijolos, vidro, plásticos, componentes, como portas, janelas e instalações sanitárias e elétricas (COELHO; BRITO, 2012). No caso da madeira como material de construção, têm sido feitos esforços nos últimos anos para implementar princípios de projeto para a desconstrução, os edifícios construídos com elementos de vedação pré-montados com woodframe, podem ser facilmente desmontados após a sua vida útil, e a redução de produtos químicos na preservação da madeira facilita a reutilização como material secundário (HÖGLMEIER; WEBER-BLASCHKE; RICHTER, 2017). A pedra natural usada em edifícios antigos foi, muitas vezes, reutilizada em novas construções e pode voltar a ser cortada em uma pedra com novo formato, pois tem uma elevada durabilidade e é fácil de desmontar se for colocada com argamassas de cal ou conexões de encaixe. No entanto a argamassa mais utilizada atualmente em serviços de cantaria é constituída por cimento Portland, o que dificulta o processo de separação (WEBSTER; COSTELLO, 2005).

Consoante Akbarnezhad, Ong e Chandra (2014) apontam, a reciclagem de concreto envolve uma energia intensiva de trituração e processos de triagem, que, juntos com o transporte para o local de reciclagem, pode resultar numa enorme quantidade de consumo de energia e, portanto, emissões de carbono. As opções para quando um material ou componente atinge o fim de seu ciclo de vida são a reutilização, a reciclagem, a incineração e a deposição em aterros sanitários. Esta última opção é a pior de todas devido a energia incorporada não ser usada e haver um alto potencial de contaminação dos solos, ar e água. A combustão é uma forma de recuperar uma parte da energia incorporada em alguns materiais como plásticos. Contudo a combustão também gera grandes quantidades de gases e resíduos tóxicos, devendo-se optar pela reutilização e reciclagem.

A maior conscientização entre proprietários, engenheiros e sociedade sobre a importância da sustentabilidade na indústria da construção, bem como os potenciais benefícios econômicos da desconstrução aumentaram nas últimas décadas. Como resultado, maior atenção tem sido dada à substituição da demolição tradicional e do envio dos materiais para aterros por estratégias mais elaboradas para a desconstrução, nas quais a energia e o capital investido em componentes de construção sejam total ou parcialmente reutilizáveis ou recicláveis (AKBARNEZHAD; ONG; CHANDRA, 2014).

O governo deve ser um fator importante para apoiar financeiramente os empreiteiros de demolição na execução da reutilização e reciclagem, ou na adoção de métodos de demolição que gerem menos desperdícios (CHEN; LU, 2017).

Há um consenso geral sobre o que se considera demolição; segundo Thomsen, Schultmann e Kohler (2011), é a eliminação completa de todos os elementos de um edifício em um determinado local e horário específico, ou seja, o fim da vida útil para a construção.

No entanto a demolição parcial, na verdade, começa durante a vida útil dos edifícios como manutenção e adaptação, incluindo a substituição de componentes e materiais de construção (THOMSEN; SCHULTMANN; KOHLER, 2011). Esse processo significa o desmantelamento ou destruição de qualquer edifício ou qualquer parte deste, por meio de métodos pré-planejados e controlados. Os métodos de demolição podem variar, dependendo do objetivo, do local onde será realizado, tempo disponível, materiais e componentes de construção que constituem o edifício. 
Addis (2010) defende que a demolição seletiva é o processo de desmontar cuidadosamente os materiais, componentes e elementos construtivos, possivelmente com alguns danos, com a intenção de reutilizar alguns deles. A desconstrução ou desmonte seletivo, de acordo com Guy, (2001), Guy, Shell e Esherick (2006), Dantata, Touran e Wang (2005), Schultmann e Sunke (2007), Coelho e Brito (2011), é o processo de desmontagem de materiais e componentes de construção na ordem inversa em relação à forma como os edifícios foram originalmente construídos. É um processo em que o último material a ser colocado é o primeiro a ser retirado (ROUSSAT; DUJET; MEHU, 2009).

Em contraste com a demolição mecânica ou mais tradicional, em que os detritos da construção civil são transportados para aterros, a desconstrução desvia os materiais do fluxo de resíduos, redirecionando-os de volta para o mercado. Os pesquisadores que estudam a desconstrução estão interessados em fechar o ciclo de vida, no qual os materiais de construção são levados de volta para o fluxo de materiais de modo a reduzir o esgotamento dos recursos naturais e a crescente pegada de carbono inerente à sua produção (DENHART, 2010).

Segundo os autores Rocha e Sattler (2009), a maior parte dos produtos de demolição no Brasil tem mau desempenho e baixo padrão de qualidade, sendo adquiridos principalmente por clientes de baixa renda, com importante limitações de recursos e de assistência técnica especializada. Os edifícios construídos convencionalmente com uma estrutura de concreto armado, e paredes de alvenaria com tubulações e condutores para fiação elétrica embutidos, dificultam a sua desmontagem e limitam a quantidade e a qualidade de componente e materiais recuperáveis. Essa inconveniência deve-se às soluções técnicas escolhidas, como a aplicação de juntas de argamassas de cimento utilizadas em ligações estruturais e não estruturais (SAGHAFITE; SHNIZI, 2011).

Um estudo em Massachusetts nos Estados Unidos da América mostra que os custos de desconstrução podem ser entre 17-25\% maior do que os custos de demolição, sendo os parâmetros que afetam esse impacto o custo da mão de obra (produtividade ou taxa horária), o custo de descarte dos materiais (taxa de depósito e transporte) e o valor de revenda de materiais recuperados (DANTATA; TOURAN; WANG, 2005). Os custos convencionais da demolição dependem muito do custo e eliminação final dos RCC, enquanto que a estrutura de custos da demolição seletiva é mais uniformemente distribuída entre mão de obra, equipamentos, custos de transporte e de eliminação final dos resíduos (COELHO; BRITO, 2011). O planejamento de uma desconstrução deve começar nos primeiros estágios do projeto da construção. Isto é especialmente importante quando a estratégia de desconstrução exige mudanças na concepção e fabricação dos componentes do edifício para possibilitar a sua desmontagem que, por sua vez, afeta o custo dos respectivos componentes (AKBARNEZHAD; ONG; CHANDRA, 2014).

\section{MÉTODO E ETAPAS DE PESQUISA}

Inicialmente foi realizado uma revisão bibliográfica em artigos, anais de congressos, teses, dissertações e livros relacionadas com os temas em estudo, demolição, demolição seletiva, desconstrução e gestão de RCC.

Complementarmente, foram analisadas legislações nacionais (ASSOCIAÇÃO BRASILEIRA DE NORMAS TÉCNICAS [ABNT], 1977, 2004), (BRASIL, 2015, 2002) e internacionais (BRITISH STANDARD INSTITUTE [BSI], 2011), (STANDARDS AUSTRALIA INTERNATIONAL [SAI], 2001), (CANADIAN STANDARDS ASSOCIATION [CSA], 2003), (NEW ZEALAND DEMOLITION AND ASBESTOS 
ASSOCIATION [NZDAA], 2013), (OCCUPATIONAL SAFETY AND HEALTH ADMINISTRATION [OSHA], 2016), (SAFE WORK AUSTRALIA, 2016) pertinentes ao processo de demolição.

A partir da pesquisa bibliográfica, foi definido que a verificação empírica do processo de demolição consideraria seis etapas, sendo estas: i. Seleção e contratação da empresa; ii. Verificações antes da demolição; iii. Documentação para a demolição; iv. Segurança na demolição; v. Execução da demolição seletiva; vi. Otimização da gestão de resíduos.

A pesquisa teve como foco caracterizar o processo de demolição de edificações de pequeno porte, e foram desenvolvidos estudos de caso exploratórios em obras de demolição de três empresas que atuam na atividade de recuperação e revenda de materiais de construção usados.

A escolha do perfil das obras e empresas estudadas surgiu porque essa configuração é usual no mercado de demolição de edificações de pequeno porte e tem grande influência nas cidades brasileiras, em especial no interior do Estado de São Paulo, região delimitada para pesquisa. A pesquisa desenvolveu-se por meio da coleta e análise de múltiplas fontes de evidência, contemplando entrevistas com perguntas abertas aos responsáveis pelas atividades de demolição, observações diretas do processo de demolição e visita às lojas de revendas dos materiais e componentes recuperados.

Foram entrevistados três empreiteiros que eram os proprietários das empresas e responsáveis pela demolição. Quanto aos empreendimentos estudados, os edifícios apresentavam o mesmo padrão construtivo, com um único pavimento térreo de uso residencial unifamiliar. Todos possuíam estrutura de concreto armado e alvenaria de tijolos maciços, a estrutura da cobertura era em madeira e o cobrimento com telhas cerâmicas, as esquadrias das janelas eram metálicas, e as portas, em metal ou madeira.

As empresas não possuíam dados precisos sobre a data e sobre a construção das edificações demolidas. Estima-se, com base nas características construtivas e arquitetônicas, que as edificações foram construídas em meados do século vinte ou posterior. As edificações encontravam-se num bom estado de conservação e habitáveis, o motivo da demolição deve-se à localização dos terrenos para a construção de edifícios familiares de múltiplos pavimentos e não pelo o seu estado de conservação.

Quadro 1- Quadro síntese da coleta de dados realizada para os estudos de caso.

\begin{tabular}{|c|c|}
\hline Estudos de Caso & Coleta de Dados \\
\hline \multirow{2}{*}{$\begin{array}{c}\text { Estudo de Caso } 1 \\
\text { (E1) }\end{array}$} & Entrevista ao Responsável \\
\cline { 2 - 2 } & Acompanhamento da demolição \\
\hline \multirow{2}{*}{$\begin{array}{c}\text { Estudo de Caso } 2 \\
\text { (E2) }\end{array}$} & Visita à loja de Revenda \\
\cline { 2 - 2 } & Entrevista ao Responsável \\
\hline $\begin{array}{c}\text { Estudo de Caso 3 } \\
\text { (E3) }\end{array}$ & Acompanhamento da demolição \\
\cline { 2 - 2 } & Acompanhamento da revenda dos materiais \\
\hline
\end{tabular}

Fonte: Autores

Com base na revisão bibliográfica, na sistematização das normas nacionais e internacionais de demolição predial e nas análises dos resultados empíricos, foram desenvolvidas diretrizes para auxiliar no planejamento da demolição seletiva de pequenas construções, tendo como foco o incremento da segurança e da eficiência nos processos de demolição. 


\section{ESTUDOS DE CASO: RESULTADOS E DISCUSSÃO}

\subsection{Caracterização do processo de demolição}

Antes de dar início ao processo de demolição, deve-se solicitar, na prefeitura municipal, uma autorização para efetuar a demolição, designada Alvará de Demolição, que deve conter a duração da execução da demolição, e, após a execução da demolição e da remoção do entulho gerado, a prefeitura deve ser notificada da finalização dos trabalhos de demolição para agendar uma visita ao local. Depois de verificada a finalização dos trabalhos, deve ser solicitado um novo prazo para a obtenção da certidão do terreno. Após a obtenção da certidão, esta deve ser entregue num cartório para registro e averbação da demolição. Para finalizar, deve ser solicitada a nova matrícula do imóvel, incluindo o histórico do terreno que contém todas as informações das atividades de construção civil desenvolvidas nesse terreno, em que será registrado o final da demolição e designado como terreno vazio.

O processo de demolição investigado caracteriza-se pela simplicidade e pelo baixo nível de mecanização. É comum que o trabalho de demolição seja executado em troca dos materiais recuperados ou tendo estes como parte da remuneração da empresa que executa o serviço.

As empresas que atuam nesse seguimento são pequenas e de abrangência local. O objetivo das empresas resume-se a demolir o edifício dentro do prazo estipulado e, ao longo das atividades da demolição, conseguir recuperar o máximo de materiais e componentes possíveis para revenda, o que, por vezes, torna-se inviável devido ao tempo reduzido para a execução dos serviços ou à dificuldade de desmontar os componentes construtivos sem danificá-los. Nesses casos, opta-se por uma demolição mais mecanizada.

Elementos de construção típicos de época, madeira e tijolos de demolição estão entre os materiais recuperados de maior valor de revenda, sendo um diferencial arquitetônico para novos projetos. Esquadrias metálicas, pias e louças recuperadas também são comercializadas, mas para um público de menor poder aquisitivo, como forma de economizar na construção de edificações populares ou temporárias. Dessa forma, os processos de demolição se orientam para recuperação seletiva desses materiais.

\subsection{Estudo de caso I}

A Empresa E1 atua como demolidora e revendedora dos materiais recuperados, com uma loja na cidade em que atua. A entrevista foi realizada com o responsável pelas demolições, que também é proprietário da empresa. Também foi realizada uma visita à loja de revenda, onde se encontra também o escritório da empresa.

Por meio da entrevista, foi possível entender o funcionamento do processo da revenda dos materiais e componentes construtivos. O entrevistado afirmou que há preocupação com a gestão dos materiais dentro do canteiro de obras, e que o desempenho de uma demolição seletiva depende significativamente do planejamento prévio ao processo de demolição, com impacto na quantidade e da qualidade dos materiais recuperados. Entretanto as verificações in loco apontaram para um processo pouco formalizado de planejamento das atividades.

A visita à loja possibilitou verificar como é efetuada a venda dos materiais que são reaproveitados, e como é gerenciado o seu depósito. Tal como foi explicado durante a entrevista, existe bastante procura pelos materiais em segunda mão, não só pelos seus preços inferiores 
em relação aos novos, como também pela qualidade superior de alguns materiais, que, por vezes, aumenta o seu preço relativamente aos novos. Segundo o proprietário, os materiais mais procurados são a madeira, o tijolo maciço e a telha cerâmica, que se justifica pela sua elevada qualidade em comparação com os novos materiais fabricados.

Figura 1 - Loja de revenda dos materiais recuperados da Empresa (E1)

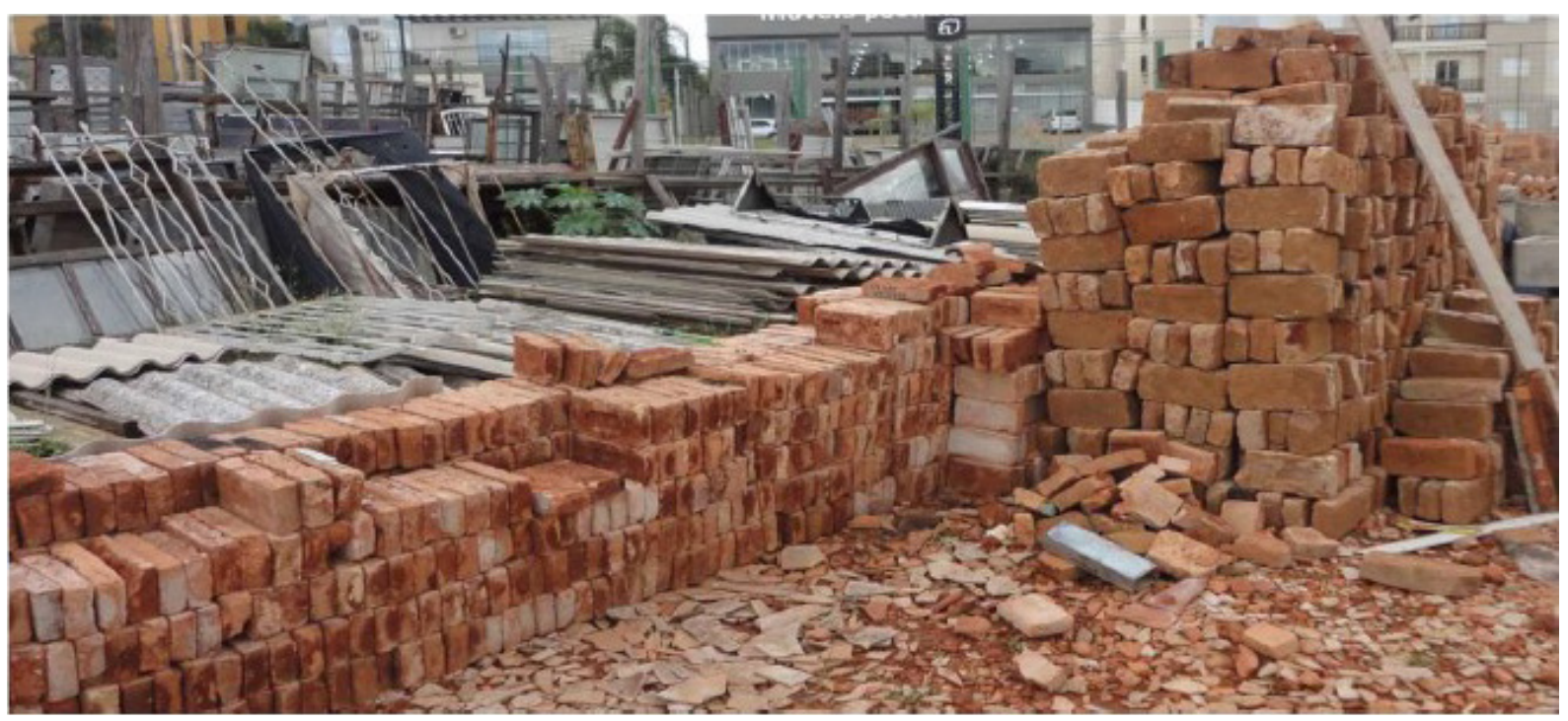

Fonte: Autores

Todos os materiais à venda possuem o preço descrito no próprio artigo, de modo a facilitar a venda dos produtos, pois não existe um registo com a quantificação dos materiais estocados em loja, nem quais são vendidos, apenas são transportados por um caminhão e depositados na loja. Observou-se que existe uma grande variedade de materiais recuperados à venda, apesar do estado de degradação em que se encontram alguns, precisando de uma recuperação ou manutenção, o que provoca uma grande variação nos preços atribuídos.

Foram também efetuadas algumas visitas a duas obras de demolição seletiva de habitações unifamiliares térreas e um breve acompanhamento do processo de demolição. Em ambos os processos, se optou por iniciar por uma demolição manual, com o auxílio de equipamentos manuais como martelo e picareta; apenas utilizam-se equipamentos mecânicos, como a escavadeira, para limpeza do terreno e remoção do entulho, ou para derrubar algum elemento estrutural, cuja demolição manual seja difícil. Foi possível observar que não existia qualquer tipo de documento em obra, como as medidas de segurança, um plano de gerenciamento de resíduos, ou mesmo um cronograma para a execução dos trabalhos.

O primeiro passo a ser dado durante o processo da demolição seletiva é a remoção dos elementos não estruturais, como as portas e janelas. Inicia-se então por retirar todas as esquadrias manualmente. $\mathrm{O}$ depósito dos materiais é efetuado ao longo da habitação, como se pode verificar na figura 2, devido à falta de espaço e à ausência de um local para o armazenamento em obra, até serem transportados para a loja. 
Figura 2 - Recuperação de portas e janelas pela demolição seletiva

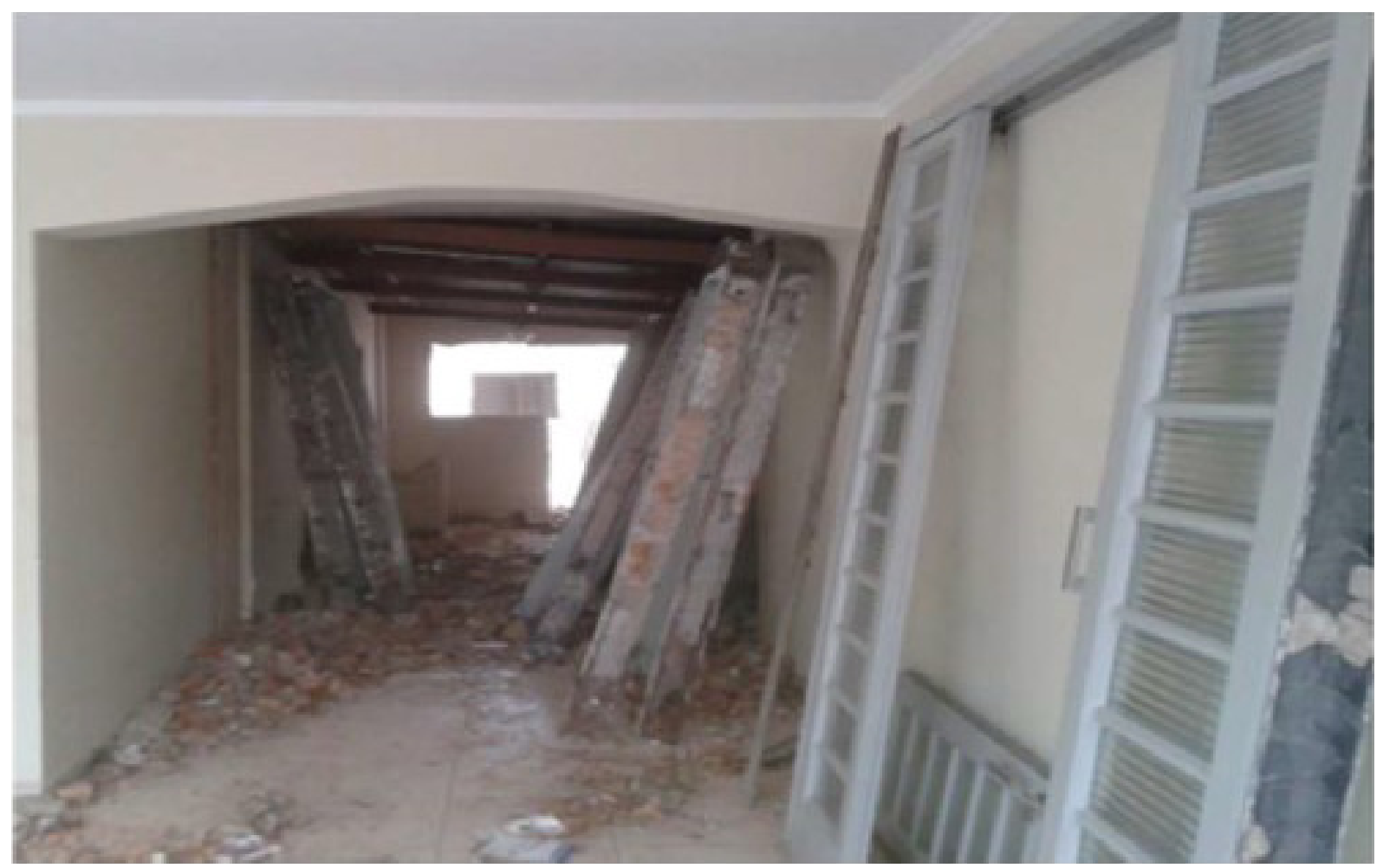

Fonte: Autores

O próximo passo a executar é retirar toda a cobertura do edifício. Durante essa tarefa, é necessário ser extremamente cuidadoso, devido ao fato de as telhas cerâmicas serem um material muito frágil, quebrando-se muito facilmente no decorrer do processo de demolição, provocando, assim, desperdício de material que poderia ser reutilizado, como também o aumento da quantidade de resíduos em obra, acumulando entulho no pavimento do local de trabalho.

Constatou-se também que não existe nenhum tipo de separação em obra, nem classificação de resíduos, apenas uma junção de todo o entulho acumulado que era posteriormente transportado por um caminhão, para o local de despejo. Em nenhuma das obras da empresa acompanhadas, foi encontrado repositório adequado para os materiais e entulho, como por exemplo, caçambas.

Durante o acompanhamento realizado à segunda obra dessa empresa, foi observada a falta de equipamentos de proteção individual (EPI) e equipamentos de proteção coletiva (EPC). Os trabalhadores não utilizam capacete de proteção, nem luvas e óculos de proteção contra poeiras, e alguns trabalhadores nem possuem roupas que cubra todo o corpo durante o trabalho, deixando os braços e as pernas desprotegidos, possibilitando a ocorrência de pequenos acidentes, como cortes e arranhões. Em nenhuma das obras da empresa E1, foi encontrado sinalização sobre o uso obrigatório dos EPI e EPC, nem a presença do responsável de obra. Para finalizar o processo de demolição, é realizada a limpeza do terreno. O entulho é agrupado com o auxílio da escavadeira, para, em seguida, ser colocado num caminhão e enviado para o aterro. 


\subsection{Estudo de caso II}

O segundo estudo de caso iniciou-se pela entrevista com o responsável pela demolição, que era também responsável pela revenda dos materiais recuperados e dono da empresa, sendo esta uma empresa construtora que realiza as próprias demolições. Diferente do primeiro estudo de caso, em que a empresa possui uma loja, esses materiais são vendidos no local da demolição, durante a execução dos trabalhos, expostos ao longo do canteiro de obras e na própria calçada.

A demolição procedeu-se do mesmo modo que o estudo de caso 1. Nas pequenas obras de demolição, em que existe uma prática mais manual na execução dos trabalhos, torna-se possível a recuperação de grande parte dos materiais de construção, em comparação com uma demolição mais mecanizada e, dependendo também do interesse do seu responsável, nos materiais a recuperar. Na figura 3, é possível observar a demolição manual das paredes exteriores em tijolo maciço; desse modo, é possível recuperar o tijolo para revenda. Alguns dos materiais e componentes de construção mais recuperados são a madeira, as telhas de fibrocimento, tijolos, os lavatórios de cozinha, como banca e os lavatórios de banheiro, as portas, os portões, as janelas e os vidros.

Figura 3 - Demolição manual das paredes exteriores
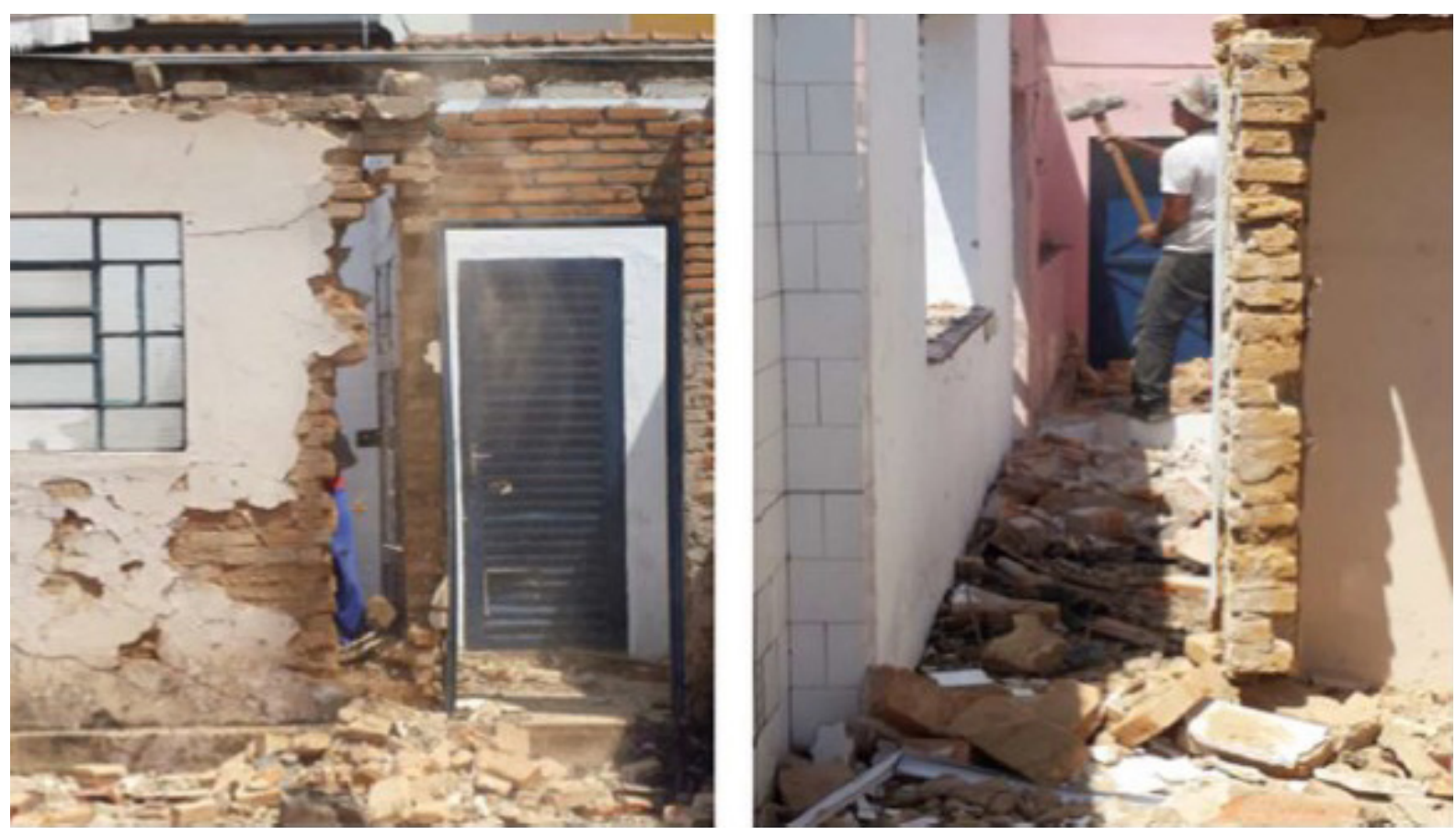

Fonte: Autores

Todos os materiais recuperados foram revendidos em obra, os clientes passavam pelo local, verificavam se tinham interesse em algum material e compravam. A figura 4 demonstra o acompanhamento da revenda de alguns materiais como o transporte de tijolo maciço, metais e madeira, entre outros. 
Figura 4 - Revenda dos materiais e componentes de construção em obra.
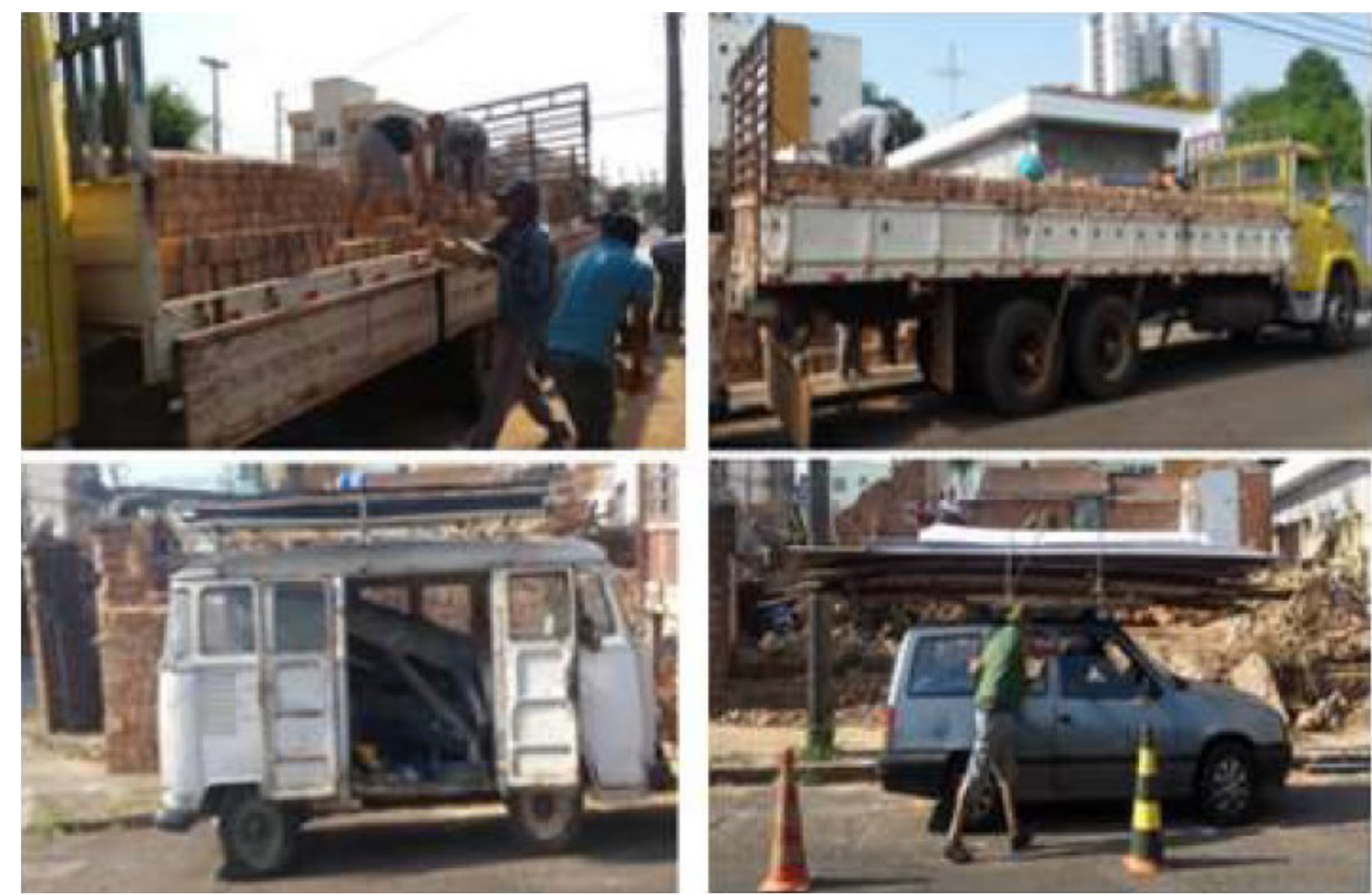

Fonte: Autores

\subsection{Estudo de caso III}

Por meio da entrevista realizada, foi possível entender o funcionamento da empresa na área das demolições, que se encontra no mercado há 30 anos e já executou trabalhos de construção, limpeza do terreno e movimento de terra, apesar de não ser este o foco da empresa. Durante a entrevista, foi possível compreender quais são as principais tarefas executadas e como são executadas durante a demolição, quais os materiais mais recuperados, como é realizada a sua remoção e armazenamento em obra e qual a sua procura em mercado de reutilizados, e para onde são enviados. Por falta de obras de demolição, não foi possível fazer o acompanhamento da execução de uma demolição seletiva realizada por essa empresa.

A loja é um local de estocagem dentro da casa do proprietário da empresa, com pouco espaço e em condições bastante precárias, sem qualquer proteção contra intempéries, ficando distribuídos pelo jardim em contato com o solo, acabando por enferrujar e degradar parte dos elementos expostos, como portas, janelas, grades metálicas, portões, entre outros, como se pode ver na figura 5 . O proprietário possui também outro local para estocagem, que utiliza para guardar alguns dos materiais para revenda. 
Figura 5 - Estocagem dos materiais na loja da empresa (E3)
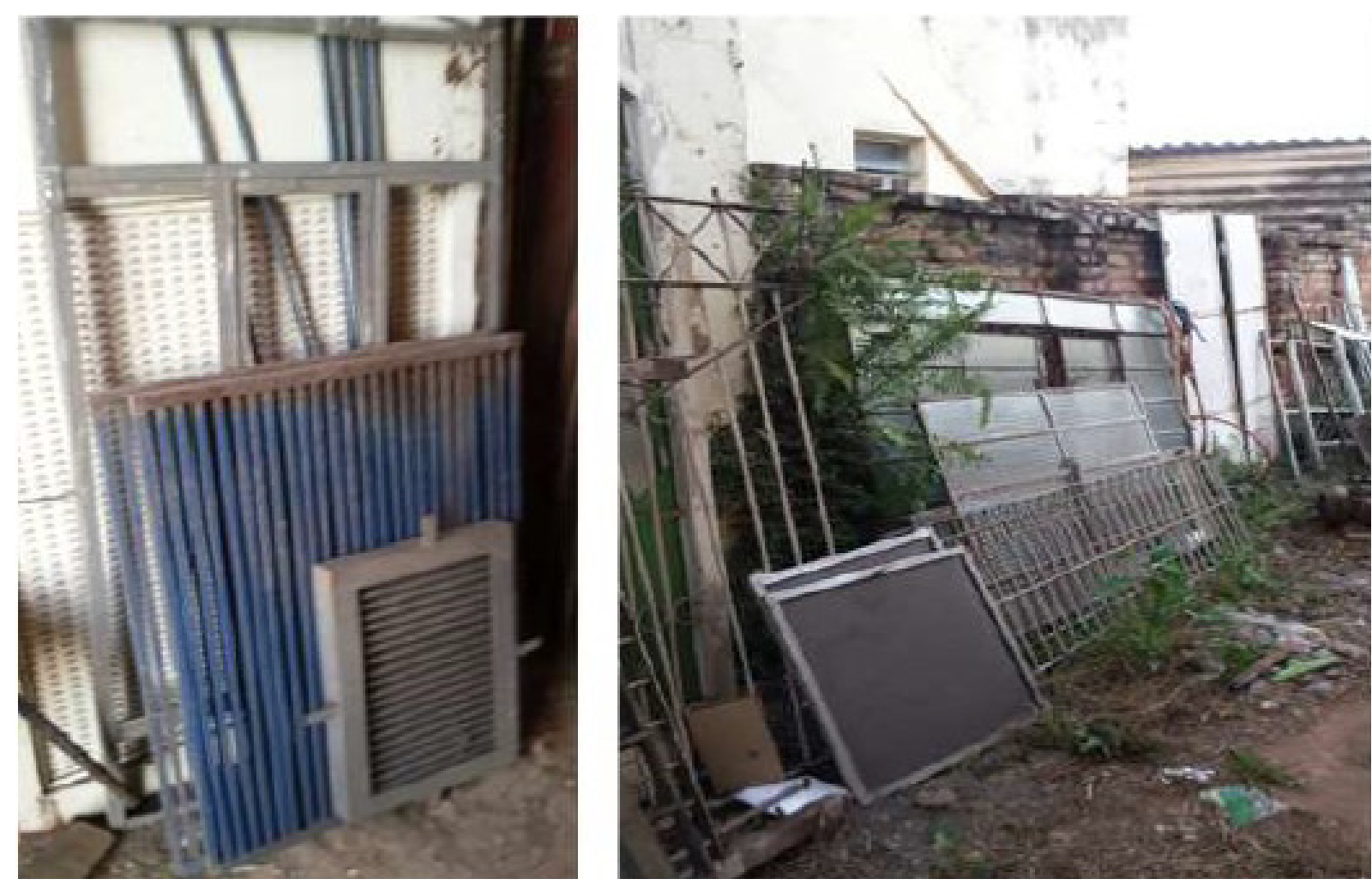

Fonte: Autores

Tal como foi explicado anteriormente na empresa E1, o mesmo se sucede nessa empresa; existe bastante procura pelos materiais em segunda mão, não só pelos seus preços inferiores em relação aos materiais novos, como também pela qualidade superior de alguns materiais, que é o caso da madeira. Mas existe também uma procura de elementos construtivos e decorativos, com valor histórico, como portas de fazendas antigas, ou candelabros, entre outros, elementos com pormenores artísticos, que, após o seu restauro, podem ser vendidos a um preço muito superior ao original.

\subsection{Análise de resultados}

Segundo Addis (2010), a opção mais fácil é demolir um edifício o mais rapidamente possível e ganhar o máximo vendendo os materiais recuperados, partindo do princípio de que a empresa é proprietária dos materiais e sempre tentarão reduzir ao máximo a quantidade de resíduos despejados em aterros, por causa do seu custo. Essas empresas resgatam e reaproveitam os elementos e materiais construtivos que podem ser facilmente retirados de uma construção e que possuem um valor alto o suficiente para cobrir os esforços e cuidados necessários, para mantê-los em boas condições. Ou seja, nenhuma demolidora irá preservar um elemento que não possa ser vendido rapidamente, mantendo assim os seus custos de armazenamento baixos, principalmente se forem necessários cuidados especiais para a remoção do material, para garantir que possa ser reutilizado.

Conclusões semelhantes foram alcançadas com base nos diferentes estudos de caso. Após a aprovação do alvará de demolição pela prefeitura, não foi encontrado nenhum documento em obra, apenas é realizado uma vistoria visual por parte do responsável para verificar quais os 
materiais e elementos de maior valor comercial. Nem existe um planejamento das atividades a executar, apenas a prática convencional. Por conseguinte verificou-se que essas empresas usam o mesmo processo de demolição seletiva, iniciado por uma demolição manual, de modo a recuperar o máximo possível de materiais e elementos construtivos, e posteriormente uma demolição mecânica com o auxílio da máquina escavadora, para derrubar os elementos da estrutura mais reforçados, por vezes vigas e pilares de concreto armado, que inicialmente não seria possível demolir manualmente ou até o pavimento térreo e as fundações, finalizando com limpeza do terreno.

Constatou-se também que não se seguem as medidas de segurança, os trabalhadores estão sujeitos a riscos de queda de materiais, ou acidentes de trabalho. Algumas das empresas não têm um responsável em obra permanentemente, apenas permanecem os trabalhadores, que não são obrigados a utilizar os EPIs, como capacete de proteção, botas, óculos, luvas, roupa coberta e cintos de segurança, nem os EPC, como andaimes, redes ou tapumes. E inexiste uma proteção do canteiro de obras, em contato com a calçada e o público, precavendo a queda de materiais e detritos ou poeiras. Não é comum sinalização em obra a identificar o local de demolição, nem dos EPI, algumas empresas nem a sua identificação colocam, ficando sem saber qual a empresa de demolição que executou o serviço. Foi constatado que são escassas as informações transmitidas aos trabalhadores sobre o plano de demolição, e não há treinamentos formais relacionados à segurança em obra ou referentes a técnicas e execução das atividades de demolição. Não existem grandes incentivos, no sentido de recuperar o máximo possível de materiais e elementos para reciclagem, o que fica evidente na falta de preocupação quando à forma como são dispostos e armazenados em obra os materiais não comercializáveis.

Como referido anteriormente, apenas os materiais fáceis de recuperar e com valor comercial foram separados e armazenados. Os materiais recuperados são enviados para as lojas de venda em segunda mão, ou vendidos no próprio local de trabalho.

Tal como aconteceu em obra, foi possível verificar que, na loja de revenda visitada, também há deficiências quanto à proteção dos materiais, muitos são deixados às intempéries, degradando-se com o passar do tempo.

Nas entrevistas com os empreiteiros dos estudos de caso, foi apontado que os materiais de demolição mais procurados são os tijolos maciços, telhas de cerâmica e madeira, por exemplo a Peroba Rosa. De acordo com as entrevistas, os clientes preferem esses materiais pela qualidade de fabricação e pelo aspecto antigo, no caso de materiais cerâmicos; já a Peroba Rosa é uma madeira rara e muito procurada para a fabricação de móveis, pois pode durar mais de 100 anos. Além destes, todos os materiais metálicos são recuperados, entre outros elementos como portas, janelas, banheiros, móveis, pias de cozinhas, vidro e telhas de fibrocimento. Pela falta de cuidado durante a demolição, é acumulada uma grande variedade de resíduos. Tudo o que se torna resíduo é enviado para o aterro da cidade, para eventualmente ser reciclado.

A figura 6 é um fluxograma das atividades realizadas pelas empresas, demonstra as possíveis trajetórias finais dos materiais e componentes de construção, estes são as opções adotadas atualmente pelas empresas, relativamente à destinação final. Quanto às atividades de demolição, o foco das pequenas empresas ainda é apenas executar a demolição de edifícios o mais rápido possível, aproveitando um maior número de materiais, sem uma separação correta de resíduos no canteiro de obra. Através do quadro 2, é estabelecido um resumo das atividades realizadas pelas empresas estudadas em função das 6 etapas da demolição seletiva. 
Figura 6- Fluxograma da gestão de resíduos de demolição.

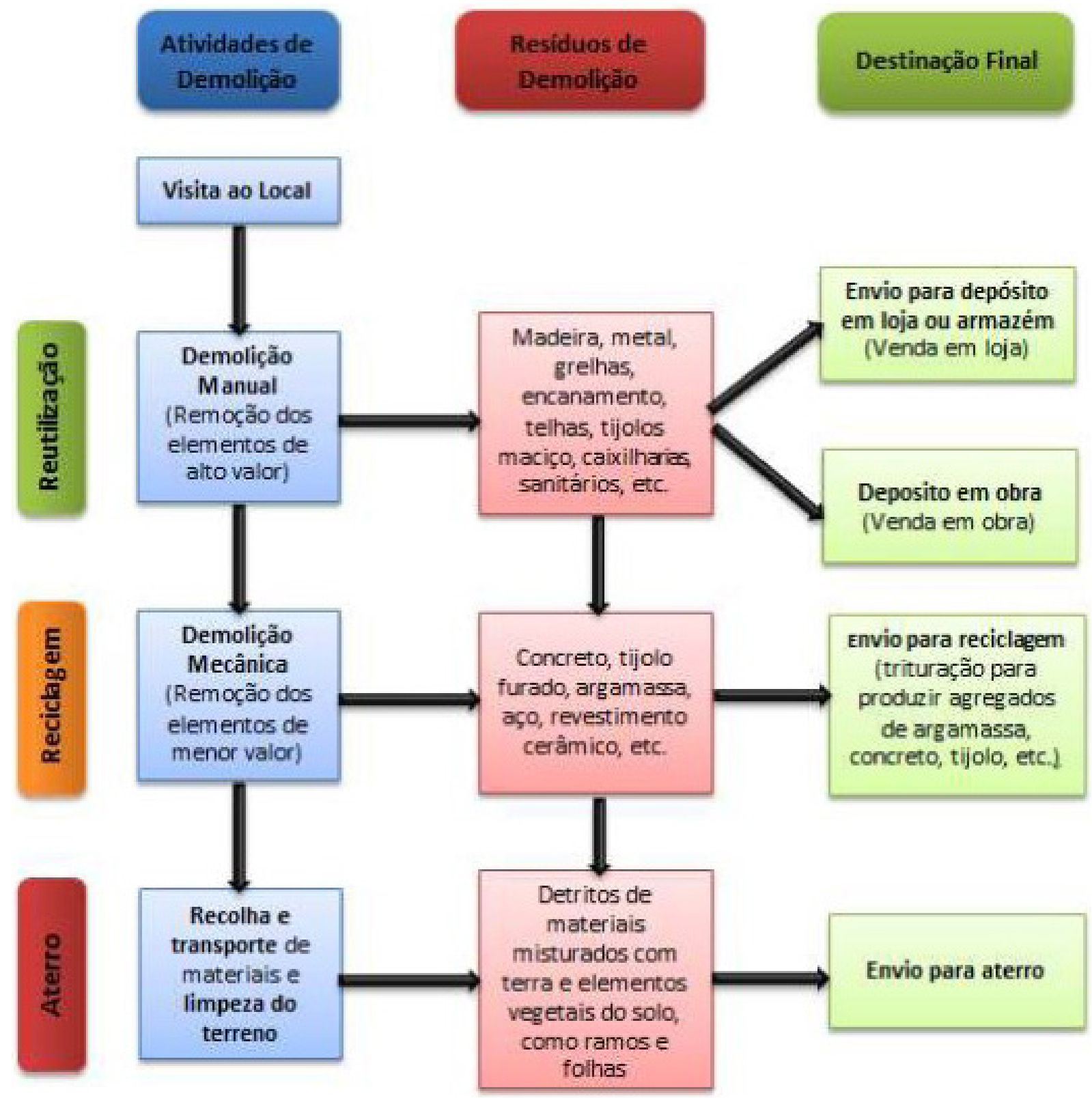

Fonte: Autores

\subsection{Diretrizes para o planejamento da demolição seletiva}

Para garantir que a execução dos trabalhos possa ser realizada com segurança, é elaborado um planejamento da demolição. Esse processo considera o ambiente inserido, a segurança do público, dos trabalhadores e outros requisitos obrigatórios, bem como as metas de custo, tempo e dos próprios clientes. Esse planejamento implica uma estreita colaboração e interação entre cliente, responsáveis pela demolição, engenheiros, arquitetos, se necessário, agências reguladoras, empreiteiros e subempreiteiros. Todas as atividades de demolição devem ser planejadas, projetadas e realizadas dentro de um contrato formal escrito e assinado. 
Quadro 2 - Quadro síntese de comparação entre estudos de caso

\begin{tabular}{|c|c|c|c|}
\hline \multirow{2}{*}{$\begin{array}{l}\text { Categorias de } \\
\text { Análise }\end{array}$} & \multicolumn{3}{|c|}{ Estudos de Caso } \\
\hline & Empresa E1 & Empresa E2 & Empresa E3 \\
\hline $\begin{array}{l}\text { Contratação da } \\
\text { Empresa }\end{array}$ & Contratada por um cliente. & $\begin{array}{l}\text { A própria empresa construto- } \\
\text { ra é que executa a demolição, } \\
\text { não há contratação oficial. }\end{array}$ & $\begin{array}{l}\text { Contratada por um } \\
\text { cliente. }\end{array}$ \\
\hline $\begin{array}{l}\text { Verificações } \\
\text { antes da } \\
\text { Demolição }\end{array}$ & $\begin{array}{l}\text { São realizadas visualmente } \\
\text { através da visita ao local. }\end{array}$ & $\begin{array}{l}\text { São realizadas visualmente } \\
\text { através da visita ao local. }\end{array}$ & $\begin{array}{l}\text { São realizadas visual- } \\
\text { mente através da visita } \\
\text { ao local. }\end{array}$ \\
\hline $\begin{array}{c}\text { Documentação } \\
\text { para a } \\
\text { Demolição }\end{array}$ & $\begin{array}{l}\text { Existe o alvará de demolição } \\
\text { para o licenciamento e o } \\
\text { comprovante de como os re- } \\
\text { síduos foram enviados para } \\
\text { um aterro registrado. }\end{array}$ & $\begin{array}{l}\text { Existe o alvará de demolição } \\
\text { para o licenciamento e o com- } \\
\text { provante de como os resíduos } \\
\text { foram enviados para um ater- } \\
\text { ro registrado. }\end{array}$ & $\begin{array}{l}\text { Existe o alvará de de- } \\
\text { molição para o licencia- } \\
\text { mento e o comprovan- } \\
\text { te de como os resíduos } \\
\text { foram enviados para } \\
\text { um aterro registrado. }\end{array}$ \\
\hline $\begin{array}{l}\text { Segurança na } \\
\text { Demolição }\end{array}$ & $\begin{array}{l}\text { Falta de utilização de EPI e } \\
\text { EPC e sinalização em obra, } \\
\text { não existe um técnico em } \\
\text { obra e uma limpeza do local } \\
\text { precária com resíduos por } \\
\text { toda a obra. }\end{array}$ & $\begin{array}{l}\text { Falta de utilização de EPI e EPC } \\
\text { e sinalização em obra, apesar } \\
\text { de existir um técnico em obra, } \\
\text { não há qualquer informação } \\
\text { ou formação sobre o traba- } \\
\text { lho. Os operários contratados } \\
\text { encontravam-se ilegais, sem } \\
\text { registro de trabalho. Existe } \\
\text { uma limpeza do local precária } \\
\text { com resíduos por toda a obra. }\end{array}$ & $\begin{array}{l}\text { Não foi possível obser- } \\
\text { var em obra. }\end{array}$ \\
\hline $\begin{array}{l}\text { Execução da } \\
\text { Demolição }\end{array}$ & $\begin{array}{l}\text { Execução de uma demolição } \\
\text { manual de modo a retirar } \\
\text { todos os materiais possíveis } \\
\text { em obra. Os elementos es- } \\
\text { truturais resistentes eram } \\
\text { derrubados pela demolição } \\
\text { mecânica com auxílio de } \\
\text { uma máquina escavadeira. }\end{array}$ & $\begin{array}{l}\text { Execução de uma demolição } \\
\text { manual de modo a retirar to- } \\
\text { dos os materiais possíveis em } \\
\text { obra. Os elementos estrutu- } \\
\text { rais resistentes eram derruba- } \\
\text { dos pela demolição mecânica } \\
\text { com auxílio de uma máquina } \\
\text { escavadeira. }\end{array}$ & $\begin{array}{l}\text { Não foi possível obser- } \\
\text { var em obra. }\end{array}$ \\
\hline $\begin{array}{l}\text { Otimização da } \\
\text { Gestão de } \\
\text { Resíduos }\end{array}$ & $\begin{array}{l}\text { Sem separação de resíduos } \\
\text { em obra, apenas os mate- } \\
\text { riais e elementos eram sepa- } \\
\text { rados e enviados para a loja. } \\
\text { Os resíduos eram acumula- } \\
\text { dos e transportados por um } \\
\text { caminhão para aterro. }\end{array}$ & $\begin{array}{l}\text { Sem separação de resíduos } \\
\text { em obra, apenas os materiais } \\
\text { e elementos eram separados } \\
\text { e enviados para a loja. Os re- } \\
\text { síduos eram acumulados e } \\
\text { transportados por um cami- } \\
\text { nhão para aterro. }\end{array}$ & $\begin{array}{l}\text { Não foi possível obser- } \\
\text { var em obra. Os mate- } \\
\text { riais e elementos recu- } \\
\text { perados são separados } \\
\text { para serem enviados } \\
\text { para a loja. }\end{array}$ \\
\hline
\end{tabular}

Fonte: Autores.

As diretrizes foram divididas em seis partes que correspondem a diferentes etapas do processo da demolição, sendo estas:

\section{- Contratação da empresa}

Refere-se à escolha da empresa que irá executar a demolição, e ao processo de contratação.

\section{- Verificações antes da demolição}

Nessa fase, deve-se solicitar o desligamento dos serviços públicos de água, energia e gás. Seguem-se as verificações a serem realizadas antes de iniciar os trabalhos de demolição, ou 
seja, as vistorias a serem efetuadas ao edifício, a caracterização dos materiais constituintes, a sua toxidade, e o estado em que se encontra o edifício e os adjacentes. Estas são as medidas preparatórias, para a elaboração e desenvolvimento de um plano de atividades, e, para tal, é necessário efetuar uma visita ao local de modo a verificar o estado em que o edifício se encontra, sendo analisado e observado por técnicos competentes. É necessária a elaboração de uma lista dos materiais que contêm riscos especiais, ou que contêm valor arquitetônico e só posteriormente a essa análise e que é será realizada uma avaliação estrutural prévia à demolição.

\section{- Documentação para a demolição}

A terceira etapa descreve a documentação exigida pela prefeitura municipal e outros documentos importantes, como um plano para a demolição, um plano de segurança e saúde e um plano de gestão de resíduos, que irão auxiliar a execução das atividades dentro do canteiro.

\section{- Segurança na Demolição}

A seguinte etapa define as regras de segurança a serem aplicadas dentro do canteiro de obra e os respetivos equipamentos de proteção a serem utilizados. O empreiteiro deve tomar uma série de medidas para proteger a saúde e a segurança dos trabalhadores, através da supervisão e treinamento dos trabalhadores. Essas operações preparatórias envolvem um planejamento global dos trabalhos, incluindo os métodos a serem usados para desmantelar a estrutura, os EPI e EPC, e as medidas preventivas para a realização segura trabalhos.

\section{- Execução da demolição seletiva}

Como recomendação geral, o desmonte do edifício deve ocorrer na direção oposta da sua construção lógica. O processo costuma se iniciar com a retirada dos acabamentos e depois segue de forma descendente do desmonte da cobertura, desmonte das vedações e das instalações, passando pela demolição das estruturas e, por fim, das fundações.

O processo de demolição deve começar com a remoção controlada de materiais perigosos, por exemplo, o amianto, entre outros (ABNT, 1977). Posteriormente se procede à desmontagem dos elementos arquitetônicos recuperáveis que não pertencem à estrutura do edifício e os acabamentos que não são suporte de outros elementos. São determinados os componentes e outros elementos valiosos que podem ser retirados na "primeira limpeza" (também conhecido como "soft strip", que é o estágio inicial do processo de demolição seletiva, durante o qual os elementos com maior valor monetário e mais fáceis de remover são retirados antes do desmantelamento do edifício, de modo a evitar danos) (ADDIS, 2010). Em seguida, deve ser retirada a estrutura da cobertura para diminuir o peso sobre as janelas e portas e assim facilitar o desmonte desses elementos.

A desmontagem em planos inclinados deve ser iniciada pela cumeeira, seguindo o sentido descendente até ao beiral. Durante a remoção progressiva de elementos estruturais nas coberturas inclinadas, devem sempre ser deixadas terças, ripas e caibros suficientes para garantir a estabilidade estrutural, enquanto a desmontagem prossegue, por meios manuais. Se for necessário, devem ser usados contraventamentos provisórios.

O desmonte de vedações e estruturas deve se dar das camadas exteriores até às camadas interiores, ou seja, primeiro devem ser removidos os materiais do revestimento exterior, 
em seguida, o plano de apoio (ABNT, 1977). Passa-se depois para a demolição das paredes até o edifício resumir-se unicamente à parte estrutural. Para tal, é necessário retirar as vigas, paredes e os pilares que se apoiam na laje, sendo estes os últimos elementos. Caso não seja possível a reutilização de elementos de construção estruturais, procede-se à demolição da estrutura.

\section{- Otimização da gestão de resíduos}

A última etapa proposta versa sobre a gestão dos resíduos, que define como deve ser desenvolvido o gerenciamento dos resíduos em obra e qual a melhor destinação final. Na obra, deve-se realizar a separação e acondicionamento de materiais de maneira a otimizar o layout do canteiro de demolição, em termos da ocupação de espaço e de reduzir os transtornos aos vizinhos. É importante planejar o sistema de remoção e separação dos resíduos para otimizar processos de reciclagem e, quando possível, de disposição final em aterros controlados. O transporte dos materiais para o aterro deve considerar a segurança e o atendimento às legislações aplicáveis em termos ambientais, com a disposição em aterro licenciado etc. Finalizar a demolição com a limpeza do terreno.

A figura 7 apresenta um fluxograma de todas as seis etapas da demolição seletiva, apresentando as orientações e diretrizes sistematizadas para cada etapa do processo de demolição. 
Figura 7- Fluxograma das etapas de planejamento da demolição seletiva

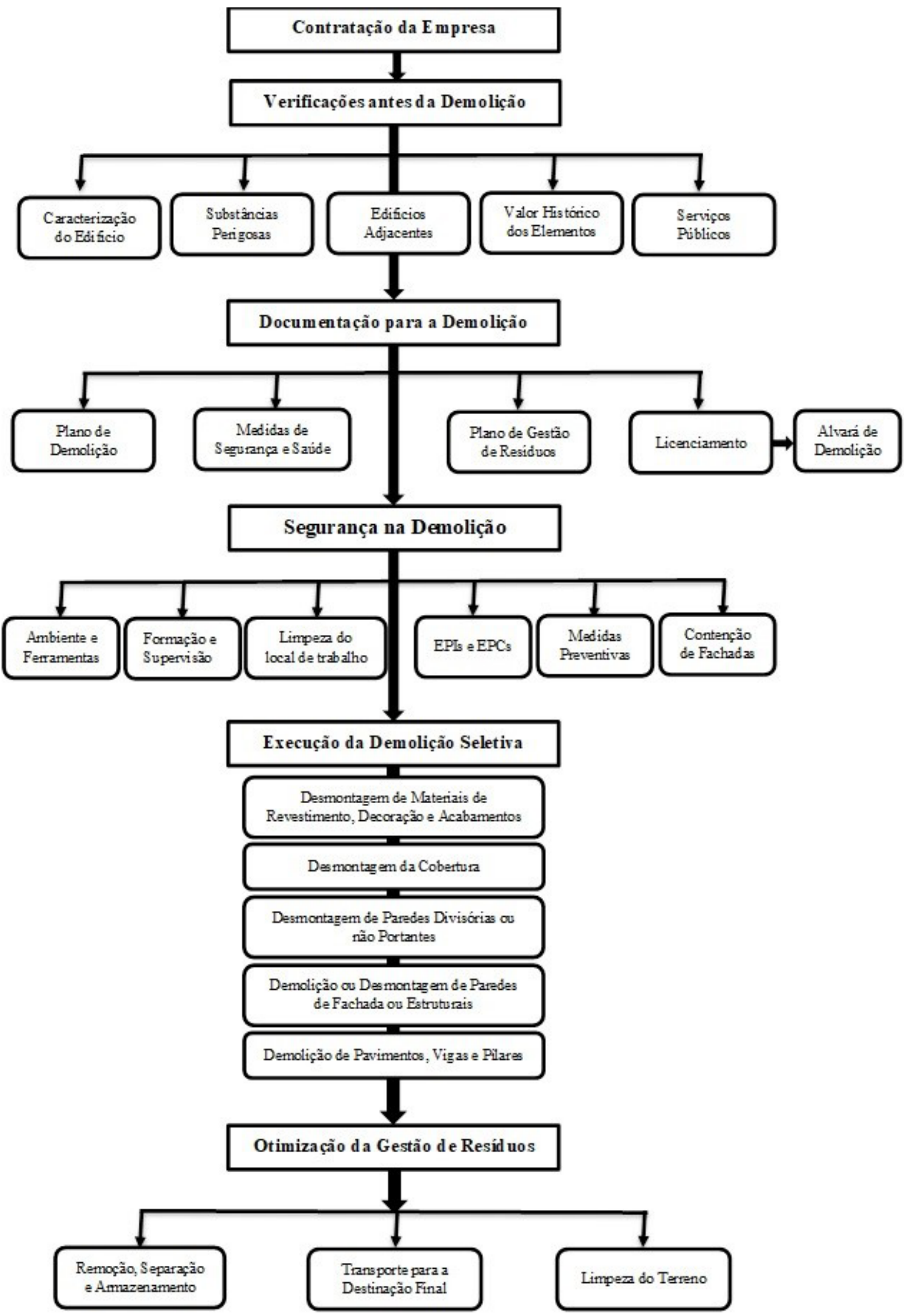

Fonte: Autores 


\section{CONCLUSÃO}

O crescimento das demolições no Brasil e o aumento das taxas de resíduos nos aterros colocam na pauta do desenvolvimento local a melhoria nos processos de demolição e manejo dos RCC.

Na pesquisa, foi verificado que não existe um planejamento formal das obras de demolição, apenas uma noção da duração e das atividades necessárias, por parte do responsável. Por mais simples que sejam as demolições, existe uma necessidade de desenvolver medidas de segurança aplicadas à demolição seletiva. É essencial a implementação de um cronograma de atividades que possibilite aos responsáveis gerirem a duração e a execução das tarefas em obra e um plano de gerenciamento de resíduos. Para tal, foram sugeridas novas estratégias para aprimorar o processo de trabalho de demolição e as regulamentações municipais relativas à atividade de demolição. A estrutura das diretrizes desenvolvidas procurou contribuir com o estado de arte teórico e com as práticas de demolição, focando as principais atividades a serem executadas em demolições seletivas, sendo que alguns aspetos devem ser ajustados à realidade de cada situação.

Destaca-se que o estudo tem duas importantes limitações. Primeiro trata-se de um tipo específico de demolições, sendo este a demolição seletiva aplicada a residências unifamiliares com pavimento térreo, com uma solução construtiva de alvenaria em tijolo maciço e cobertura em telha cerâmica com estrutura de madeira. E em segundo lugar, as práticas verificadas nos três estudos de caso são típicas do mercado local de demolição para o sistema construtivo estudado, mas o número de casos é pequeno (3), o que impede generalizações, embora, de forma analítica, possa-se argumentar que práticas semelhantes são bastante comuns no mercado regional de pequenas demolições.

Com relação às perspectivas futuras, espera-se o desenvolvimento de estratégias para a reutilização de materiais e componentes de modo a diminuir o problema urbano dos depósitos clandestinos, e torna-se necessário elaborar estudos práticos e quantitativos para avaliar os RCC originados e investigar novos métodos de demolição seletiva.

\section{Agradecimentos}

À Finep: inovação e pesquisa pelo financiamento à Rede de pesquisa INOVATEC-FINEP, ao CNPQ (Conselho Nacional de Desenvolvimento Científico e Tecnológico) e à CAPES (Coordenação de Aperfeiçoamento de Pessoal de Nível Superior) pelas bolsas de estudo que apoiaram o desenvolvimento desta pesquisa. Às Empresas de Construção e Demolição por sua prontidão para participar nesta pesquisa e, também, aos revisores do trabalho que ajudaram na correção com os seus comentários e sugestões na versão prévia deste artigo.

\section{REFERÊNCIAS}

ADDIS, B. Reuso de materiais e elemento de construção. Tradução de Christina Del Posso. São Paulo: Oficina de Textos, 2010.

AKBARNEZHAD, A.; ONG, K. C. G.; CHANDRA, L. R. Economic and environmental assessment of deconstruction strategies using building information modeling. Automation in Construction, Sydney, v. 37, p. 131-44, jan. 2014.

ASSEFA, G.; AMBLER, C. To demolish or not to demolish: Life cycle consideration of repurposing buildings. Sustainable Cities and Society, Alberta, Canada, v. 28, p. 146-53, jan. 2017. 
ASSOCIAÇÃO BRASILEIRA DE NORMAS TÉCNICAS (ABNT). NBR 100004: Resíduos Sólidos- Classificação. Rio de Janeiro, 2004.

ASSOCIAÇÃO BRASILEIRA DE NORMAS TÉCNICAS (ABNT). NBR 5682: Contratação, Execução e Supervisão de Demolições. Rio de Janeiro, 1977.

BANIAS, G.; ACHILLAS, C.; VLACHOKOSTAS, C.; MOUSSIOPOULOS, N.; TARSENIS, S. Assessing multiple criteria for the optimal location of a construction and demolition waste management facility. Building and Environment, Theassaloniki, Greece, v. 45, n. 10, p. 2317-26, out. 2010.

BRITISH STANDARD INSTITUTE (BSI). BS 6187:2011 - Code of practice for full and partial demolition. London: BSI Standards Publication, 2011.

BRASIL. Ministério do Trabalho e Emprego (MTE). Norma Regulamentadora 18- NR 18.5 Condições e Meio Ambiente de Trabalho na Indústria da Construção - Demolição. Brasília: Ministério do Trabalho e Emprego, 2015.

BRASIL. Resolução CONAMA n. 307. estabelece diretrizes, critérios e procedimentos para a gestão dos resíduos da construção civil. Diário Oficial da República Federativa do Brasil, Brasília, DF, 2002.

CANADIAN STANDARDS ASSOCIATION (CSA). S350-M1980- Code of Practice for Safety in Demolition of Structures (Design) (Reaffirmed 2003). Toronto, 2003.

CASTRO, M. F.; MATEUS, R.; BRAGANÇA, L. Práticas sustentáveis de projetos em edifícios hospitalares. Plataforma para a Construção Sustentável. 2012. Disponível em: https://repositorium.sdum.uminho.pt/ bitstream/1822/21745/4/CINCOS12_Castro_Mateus_Bragan\%C3\%A7a.pdf

CHEN, X.; LU, W. Identifying factors influencing demolition waste generation in Hong Kong. Journal of Cleaner Production, v. 141, p. 799-811, jan. 2017.

COELHO, A.; BRITO, J. Influence of construction and demolition waste management on the environmental impact of buildings. Waste Management, Lisboa, v. 32, n. 3, p. 532-41, mar. 2012.

COELHO, A.; DE BRITO, J. Economics analysis of conventional versus selective demolition- a case study. Resources, Conservation and Recycling, Lisboa, v. 55, n. 3, p. 382-92, jan. 2011.

DANTATA, N.; TOURAN, A.; WANG, J. An analysis of the cost and duration for deconstruction and demolition of residential buildings in Massachusetts. Resources Conservation \& Recycling, v. 44, n. 1, p. 1-15, abr. 2005.

DENHART, H. Deconstructing disaster: economic and environmental impacts of deconstruction in postKatrina New Orleans. Resources, Conservation and Recycling, Portland, v. 54, n. 3, p. 194-204, jan. 2010.

GUY, B. Building deconstruction assessment tool. CIB Deconstruction and Materials Reuse: Technology, Economic, and Policy, Wellington, New Zealand, p. 125-37, abr. 2001.

GUY, B.; SHELL, S.; ESHERICK, H. Design for deconstruction and materials reuse. Proceedings of the CIB Task Group 39, v. 4, p. 189-209, 2006.

HÖGLMEIER, K.; WEBER-BLASCHKE, G.; RICHTER, K. Potentials for cascading of recovered wood from building deconstruction - a case study for south-east Germany. Resources, Conservation and Recycling, Munchen, Germany, v. 117, p. 304-14, fev. 2017. 
MARINHO, J. L. A.; SILVA, J. D. Gerenciamento dos resíduos da construção e demolição: diretrizes para o crescimento sustentável da construção civil na região metropolitana do Cariri Cearense. E-Tech: Tecnologias para Competitividade Industrial, Florianópolis, v. 5, n. 1, p. 102-19, 2012.

NEW ZEALAND DEMOLITION AND ASBESTOS ASSOCIATION (NZDAA). Best practice guidelines for demolition in New Zealand. Work Safe New Zealand, 2013.

OCCUPATIONAL SAFETY AND HEALTH ADMINISTRATION (OSHA). 29 CFR 1926- Subpart $\mathrm{t}$ - Whether the demolition standard applies to moving a residential structure. USA, 2016.

PAIVA, P. A.; RIBEIRO, M. S. A reciclagem na construção civil: como economia de custos. REA. Revista Eletrônica de Administração, Franca, SP, v. 4, n. 1, p. 1-15, 2005.

ROCHA, C. A percepção sobre o conceito de desmontagem das edificações e o emprego dos materiais de demolição. In: ENCONTRO NACIONAL, 4., e ENCONTRO LATINO-AMERICANO SOBRE EDIFICAÇÕES E COMUNIDADES SUSTENTÁVEIS, 2., 2007. p. 189-97. Disponível em: http://docplayer.com.br/78272065-Apercepcao-sobre-o-conceito-de-desmontagem-das-edificacoes-e-o-emprego-de-materiais-de-demolicao. html

ROCHA, C. G.; SATTLER, M. A. A discussion on the reuse of building components in Brazil: an analysis of major social, economical and legal factors. Resources, Conservation and Recycling, v. 54, n. 2, p. 104-12, dez. 2009.

ROUSSAT, N.; DUJET, C.; MÉHU, J. Choosing a sustainable demolition waste management strategy using multicriteria decision analysis. Waste Management, Lion, v. 29, n. 1, p. 12-20, jan. 2009.

SAFE WORK AUSTRALIA. Demolition Work- Code of Practice. Australia, fev. 2016.

SAGHAFI, M. D.; TESHNIZI, Z. A. H. Building deconstruction and material recovery in Iran: an analysis of major determinants. Procedia Engineering, v. 21, p. 853-63, 2011.

SCHULTMANN, F.; SUNKE, N. Energy-oriented deconstruction recovery planning. Building Research \& Information, v. 35, n. 6, p. 602-15, set. 2007.

STANDARDS AUSTRALIA INTERNATIONAL (SAI). AS 2601:2001 - The demolition of structures. Sidney, Austrália, 2001.

TESSARO, A. B.; SÁ, J. S.; SCREMIN, L. B. Quantificação e classificação dos resíduos procedentes da construção civil e demolição no município de Pelotas, RS. Ambiente Construído, Porto Alegre, RS, v. 12, n. 2, p. 121-30, abr./jun. 2012.

THOMSEN, A.; SCHULTMANN, F.; KOHLER, N. Deconstruction, demolition and destruction. Building Research \& Information, v. 39, n. 4, p. 327-32, ago. 2011.

VEFAGO, L. H. M.; AVELLANEDA, J. Recycling concepts and the index of recyclability for building materials. Resources, Conservation and Recycling, Barcelona, Spain, v. 72, p. 127-35, abr. 2013.

WEBSTER, M. D.; COSTELLO, D. T. Designing structural systems for deconstruction: how to extend a new building's useful life and prevent it from going to waste whem the end finally comes. Greenbuild Conference, Atlanta, GA, nov. 2005. 


\section{Sobre autores:}

Andreia Sofia Moreira Martins: Doutoranda em Estruturas e Construção Civil na Universidade Federal de São Carlos (UFSCar). Mestre pelo Instituto de Arquitetura e Urbanismo da Universidade de São Paulo (USP). Graduada em Engenheira Civil no ramo de construções pelo Instituto Superior de Engenharia do Porto, Portugal. E-mail: andreiamartins282@gmail.com, Orcid: http://orcid.org/0000-0003-4781-9163

Daniel Costa Reis: Doutorando em Engenharia Civil na Escola Politécnica da Universidade de São Paulo (USP). Mestre em Arquitetura, Urbanismo e Tecnologia pelo Instituto de Arquitetura e Urbanismo (IAU-USP). Graduado em Engenharia Civil no ramo Tecnologia e Gestão das Construções pelo Instituto Superior de Engenharia do Porto, Portugal. E-mail: dreis7@gmail.com, Orcid: http://orcid.org/0000-0002-8713-5957

Márcio Minto Fabricio: Doutor em Engenharia pela Escola Politécnica da USP. Mestre em Arquitetura e Urbanismo pela EESC-USP. Docente em Arquitetura, Urbanismo e Tecnologia na Escola de Engenharia de São Carlos da Universidade de São Paulo (EESC-USP). Engenheiro Civil pela Universidade Federal de São Carlos (UFSCar). E-mail: marcio@sc.usp.br, Orcid: http://orcid.org/0000-0003-1515-6086 
